Article

\title{
Income Maximisation in a Maltese Household Photovoltaic System by Means of Output and Consumption Simulations
}

\author{
Daniele Zingariello, Marija Demicoli *(i) and Luciano Mule' Stagno \\ Institute for Sustainable Energy, University of Malta, MSD 2080 Msida, Malta; \\ daniele.zingariello@um.edu.mt (D.Z.); luciano.mule-stagno@um.edu.mt (L.M.S.) \\ * Correspondence: marija.demicoli@um.edu.mt
}

check for updates

Citation: Zingariello, D.; Demicoli, M.; Stagno, L.M. Income

Maximisation in a Maltese Household Photovoltaic System by Means of Output and Consumption Simulations. Energies 2021, 14, 7934. https://doi.org/10.3390/en14237934

Academic Editor: Pedro Dinis Gaspar

Received: 3 November 2021

Accepted: 24 November 2021

Published: 26 November 2021

Publisher's Note: MDPI stays neutral with regard to jurisdictional claims in published maps and institutional affiliations.

Copyright: (c) 2021 by the authors. Licensee MDPI, Basel, Switzerland. This article is an open access article distributed under the terms and conditions of the Creative Commons Attribution (CC BY) license (https:// creativecommons.org/licenses/by/ $4.0 /)$.

\begin{abstract}
The installation of photovoltaic (PV) systems in the Maltese Islands plays an important role in allowing Malta to increase its share in renewable energy to meet the set European Union targets. In the Maltese residential sector, PV systems are generally installed on rooftops of households with a south-facing orientation and a $30^{\circ}$ inclination angle. The scope of this study is to present a methodology to maximise the income for residents from electricity generated, by comparing the output of electricity generation with the electricity consumption patterns of different household types and consequently identifying the most favourable installation configurations of these PV systems. The research was carried out by simulating the monthly electricity generation of a 3 kilowatt-peak PV system for a year, as well as the hourly electricity generation for a day in each season of the year using the PVsyst software package. A total of 21 configurations were studied by altering the orientation and inclination angles used to install the PV system. This study confirms that a south-facing PV system inclined at $30^{\circ}$ generates the most electricity in a year. However, when compared with electricity consumption patterns of low-, medium- and high-consumption households, it is shown that a south-facing PV system inclined at $40^{\circ}$ provides a better income for residents.
\end{abstract}

Keywords: renewable energy; solar energy; PV system modelling; PV configurations; electricity consumption patterns; income maximisation

\section{Introduction}

The installation of photovoltaic (PV) panels in residential households provides communities with many benefits that can be of both an environmental and economic nature [1]. Solar energy is a renewable energy resource that can be harnessed by PV panels to generate electricity without polluting the environment with carbon dioxide $\left(\mathrm{CO}_{2}\right)$ emissions [2]. In a residential household, a PV system offsets electricity demand from the electricity grid, allowing a reduction in electricity bills for residents [3].

The increase in demand for electricity is a challenge that both developed and less developed countries must face by increasing their power generation capacities [4]. This, coupled with the ever-rising need to switch to cleaner energy technologies that do not pollute the environment, has forced countries to develop new strategies to ensure a sustainable energy mix [5]. When including the production and end-of-life treatment of a 3 kilowatt-peak ( $\mathrm{kWp}$ ) PV system, studies have shown that the total $\mathrm{CO}_{2}$ savings could amount to around $10,000 \mathrm{~kg}$ of $\mathrm{CO}_{2}$ during the lifetime of the PV system [6]. However, to promote energy generation from renewable sources, it is important that the energy source can generate electricity at a comparable cost with fossil fuel-based sources [7].

According to the current European Union (EU) directive, Malta must generate 11.5\% of its gross energy requirements from renewable sources of energy by the year 2030 [8]. Solar energy is expected to provide the largest contribution to Malta's electricity sector to help the country reach its 2030 goal. The scope of this study is thus to investigate the most favourable configurations for the installation of PV panels on residential rooftops in the Maltese Islands in order to maximise economic benefits for residents. 
The two main variables for a PV system configuration are the orientation and inclination angles which govern the placement of PV panels on surfaces [9]. In the northern hemisphere, the orientation angle of a PV system may be defined as the angle at which one orients the PV panel away from the true geographical south [10]. In the northern hemisphere, a solar panel oriented at $0^{\circ}$ will generate the most electricity at midday, when the sun's azimuth is in line with the orientation of the solar panel, meaning solar irradiation will hit the panel from directly above it [11]. At other times of the day, the sun will not be directly in front of the panels, meaning less electricity will be generated. The inclination angle, also known as the tilt angle of a PV system, can be described as the tilt of the solar panel towards the sun. The optimal inclination angle may be calculated by deducting the declination angle of the sun from $90^{\circ}$ [12]. The optimal tilt angle will vary according to the season, since the sun is lower in the sky during the winter months, while it is higher during the summer months [13].

PVsyst simulation software is used in this study to collect electricity generation data for different PV system inclination and orientation angles in Malta. A previous study comparing simulated data with observed data in Uzbekistan found that PVsyst only underestimated the electricity output by $4.68 \%$ [14]. A study performed by Nussbaumer et al. that compared simulated and observed electricity generation for a bi-facial PV module found that the PVsyst software provides accurate simulation results when irradiance is high [15]. Such studies infer that the PVsyst simulation software used in the current study will provide reliable results, especially since the latter will collect and present hourly electricity generation data on days where cloud cover is minimal.

This research article will present the electricity generation output of several PV system configurations, which include different orientation and inclination angles for the PV panels. The results will then be compared with the electricity consumption patterns of households to see which configurations provide the best economic benefit to residents. The standard configuration adopted for PV systems in Malta is to install the system south-facing with an inclination angle of $30^{\circ}[16,17]$. However, this does not necessarily mean that this is the most favourable configuration to be used in all scenarios. To date, there are no published studies identifying the best configurations for residential PV systems based on the electricity consumption patterns of households. This study will thus be the first to identify households with different consumption patterns and to compare them with electricity generation from a PV system installed with various configurations. Understanding which configuration may benefit households the most, based on their consumption patterns, will allow residents to increase their income from the installed PV systems.

Households in the Maltese Islands have different consumption levels and may also consume electricity at different times of the day [18]. It is important to understand the factors that impact electricity consumption as one would need to configure the panels in a certain way to meet the demand of consumers and to reduce the mismatch between the supply and demand of electricity [19]. Electricity demand has increased over the years in Malta, amounting to the consumption of 656.8 gigawatt-hours (GWh) in 2019, from which $8.2 \%$ was generated using renewable technologies [20]. The highest demand for electricity is usually in the months of July and August, accounting for one-fifth of the electricity consumption for the year [21].

The purpose of this study is to present a methodology on how to maximise the income for residents in a Maltese household from electricity generated from their installed PV systems by means of output and consumption simulations. The methodology adopted to achieve this scope is described in Section 2 and its aim is to determine and analyse the best PV configurations that provide the most energy to households while reducing the mismatch between electricity generation and consumer demand. Based on this methodology, Section 3 then presents the results for the electricity generation of various PV system setups as well as the results of different electricity consumption patterns throughout the four seasons. The analysis of the results is presented in Section 4 and aims to identify which of the studied configurations provides the highest benefit to residents, by comparing 
the electricity generation of each configuration with the cost of purchasing electricity from the grid and the income from selling electricity to the grid. A discussion of the results, highlighting the benefits of each configuration with respect to matching electricity demand and maximising income, is provided in Section 5. Finally, Section 6 summarises the key findings of this study, presents the concluding remarks and addresses future research directions.

\section{Methodology}

This section describes the methodology used in this study to identify different PV configurations for households with varying electricity consumption patterns, to decide on the optimal PV configurations for households in the Maltese Islands and to determine whether the electricity consumption patterns of a household impact the optimal configurations for PV panel installations. A flowchart showing the framework design for data collection and analysis is given in Figure 1.

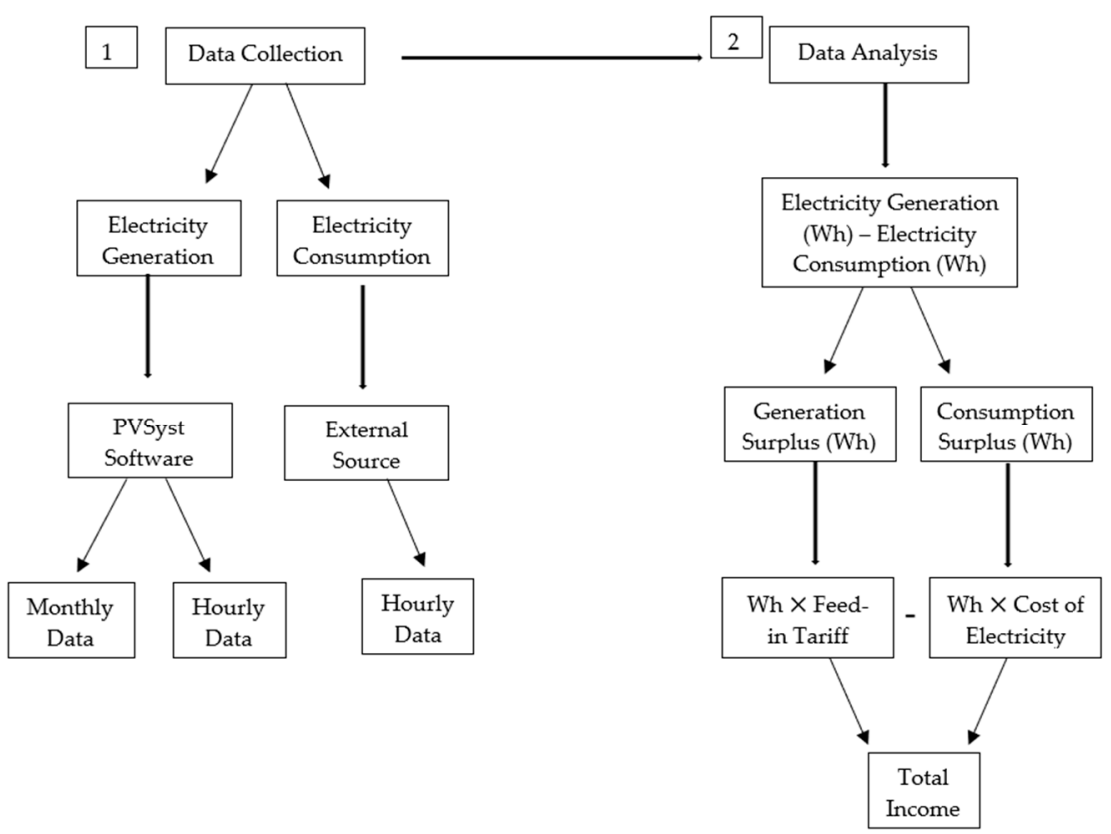

Figure 1. Flowchart of research framework design for data collection and analysis.

The software PVsyst was used in this work to simulate a grid-connected PV system installed on a rooftop with different inclination and orientation angles. PVsyst is a software package used to design, study, and predict the output of PV systems. It allows researchers to analyse a PV system's performance using different installation techniques and a variety of variables which can be modified according to the users' needs from an available database [22]. Such simulation results can be used to understand how much electricity is provided by the PV system which can then be compared to the electricity patterns of several household groups. Several factors were defined before the simulations could be performed using PVsyst, such as the location of the study, the PV system used, and the inverter required to connect the PV panels to the grid.

\subsection{Data Collection}

Weather data for the simulations were collected from the Meteonorm 7.3 database within PVsyst, with the latter having available weather data for the years between 1989 and 2003. Hourly irradiation values were collected for the selected site, which was Luqa, in Malta. The parameters used to calculate electricity generation were horizontal global irradiation, horizontal diffuse irradiation, ambient temperature, and wind velocity. 


\subsubsection{Solar Irradiation Model}

The selected solar irradiation model for this study was the Perez-Ineichen model, which is a transposition model that uses the 'horizon band' as a third component of diffuse solar irradiation [23]. This model relies on a set of empirical coefficients that define the isotropic, circumsolar and horizon components of the sky diffuse model, creating a more complex model for the calculation of diffuse solar irradiation [24].

\subsubsection{PV Panel Selection}

A 300 watt-peak (Wp) monocrystalline PV panel, with an efficiency rating of $18.45 \%$, was selected from within the PVsyst software. Since the aim of this study is to understand relative changes in electricity generation resulting from changes in the configuration of the PV system, and not in absolute values of electricity generation, the type of PV panel chosen does not impact the results of the study.

\subsubsection{PV Array Configuration}

The PV array configuration had to be defined for every run with the software. For the orientation, it was decided that the study will assess electricity generation at five different orientations, namely East, Southeast, South, Southwest, and West. Five inclination angles were also selected, starting from $0^{\circ}$ up to $40^{\circ}$, with $10^{\circ}$ intervals. A total of 21 configurations were simulated using the PVsyst software. Once all the parameters were defined, the simulations were executed to collect yearly energy yields as well as hourly data on four representative days of the year. The days chosen were representative of the four seasons, and were 15th February (winter), 14th May (spring), 15th August (summer) and 14th November (autumn). The reason behind the chosen days was that they were close to the days where electricity consumption data were available, and they were all sunny days, making sure that the data are comparable.

\subsection{Data Analysis}

The first step in analysing the data was to group the results for each respective configuration according to their orientation to show every inclination angle studied for that configuration. In addition, electricity consumption data for households were also included to allow the comparison between hourly electricity generation and consumption of low-, medium-, and high-consumption households within the Maltese Islands.

The next step of analysis was to compare the hourly data for electricity generation and consumption to see which of the studied configurations provided the best income opportunity for residents. First, the hourly electricity consumption data were deducted from its respective hour of electricity generation to obtain the difference between electricity generation and consumption in watt-hour (Wh). If the result of this calculation was positive, then this meant that during that hour, there was a surplus of electricity generation from the PV system, while if the answer were negative, it meant that the demand for electricity from the household was more than the PV system could provide.

The final step of the process was to multiply the result by the cost of electricity for the household if negative, or the applicable electricity feed-in tariff if the result showed a surplus in electricity generation. The cost of electricity was based on the amount of electricity the house would consume in 61 days, since in Malta, electricity bills are sent to residents every 2 months. Table 1 shows the electricity consumption tariffs chosen for each month and for each type of household. The different electricity consumption tariffs for the different households are due to the fact that in Malta there is an escalating price for different use bands. Once all the steps were completed for each month, the total values were summed up to provide the total income obtained from each configuration. 
Table 1. Electricity consumption tariffs chosen according to consumption level for each season studied.

\begin{tabular}{cccc}
\hline Month & Low-Consumption $(\boldsymbol{\epsilon})$ & Medium-Consumption $(\boldsymbol{\epsilon})$ & High-Consumption $(\boldsymbol{\epsilon})$ \\
\hline February & 0.1047 & 0.3420 & 0.6076 \\
May & 0.1047 & 0.1607 & 0.6076 \\
August & 0.1298 & 0.3420 & 0.6076 \\
November & 0.1047 & 0.1607 & 0.6076 \\
\hline
\end{tabular}

\subsection{Limitations of the Study}

One limitation of this study is the fact that hourly data were collected for four days of the year, which means that the benefits received from the PV system on these days may not be fully representative of all the benefits each configuration may provide during the whole year. To tackle this limitation, data were also collected monthly for a whole year to understand which configurations provide the most electricity generation yearly, and to compare these results with Malta's monthly electricity consumption figures.

Another possible limitation is that this study assumes that residents can install PV panels on their rooftop using any configuration studied, when in fact, planning guidelines, the building's orientation, and the presence of obstacles nearby, may not allow the PV system to be configured in certain ways. However, the results of this study aim to set a basis for future development of planning policies that promote the installation of PV systems using the most favourable configurations.

This study uses electricity consumption tariffs that are designed for a PV system used in the Maltese Islands, with a possible limitation is that this study is only relevant for Malta. However, the methodology presented and used in this study can be easily replicated for other countries by using the applicable electricity consumption tariffs in the relevant country.

\section{Results}

This section presents the results for the electricity generation of various PV system setups with different orientations and inclination angles, as well as the results for the electricity consumption patterns of low-, medium- and high-consumption households throughout the four seasons.

\subsection{Electricity Generation Results}

The results show that in a year's electricity generation of a PV system in Malta, a southfacing PV system inclined at $30^{\circ}$ generates the most electricity from all the configurations studied. This system generates 5037 kilowatt-hours $(\mathrm{kWh})$ of electricity in a year. The inclination angle of the PV system allows optimal energy generation in winter without significantly reducing electricity generation in summer. If the PV system is inclined at $40^{\circ}$, then electricity generation in winter is higher, but the energy yield in summer is reduced. The opposite is true for a PV system inclined at $20^{\circ}$ or lower, with electricity generation being optimised for summer (Figure 2). 


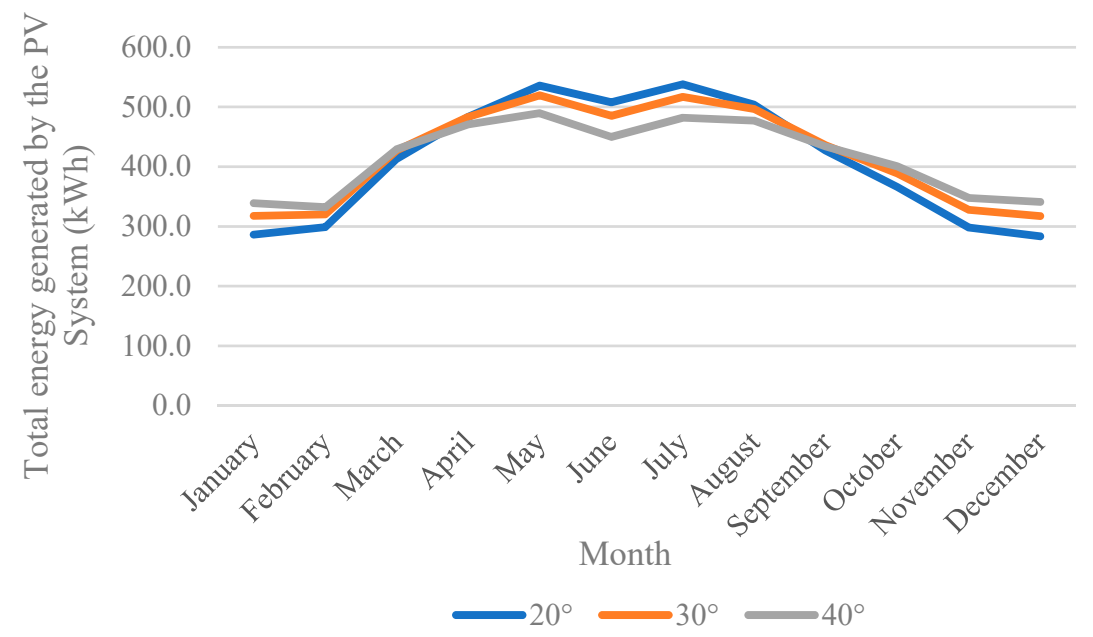

Figure 2. Comparison of the monthly electricity generation of a south-facing $3 \mathrm{kWp}$ PV system with $20^{\circ}, 30^{\circ}$ and $40^{\circ}$ inclination angles.

The results for other orientations show varying electricity generation patterns. When considering hourly data, an east-facing PV system generates considerably less electricity during a whole day. However, electricity generation in the early morning is highest for this orientation. A southeast-facing system is still optimal for morning generation of electricity, however, the energy yield during the rest of the day is not as adversely impacted as an east-facing system since the panel does not block solar irradiation as much in the afternoon. If one orients the PV system to face the southwest or west, electricity generation will be practically identical to the southeast- and east-facing counterparts, with the difference that electricity generation is optimised for the afternoon.

\subsection{Household Consumption Results}

Electricity consumption data were obtained from a secondary source of data for a group of households that were assessed in Malta during 2018. Data were collected for four days of the year (4th February, 6th May, 6th August and 5th November), in this way covering one day in each season for each of the categories. The following sections show a representation of the electricity consumption patterns per household in Malta, divided into three categories:

- $\quad$ Low-Consumption Households-Households consuming an average of $1560 \mathrm{kWh}$ of electricity per year.

- Medium-Consumption Households-Households consuming an average of 12,700 kWh of electricity per year.

- High-Consumption Households-Households consuming an average of 27,100 kWh of electricity per year.

\subsubsection{Low-Consumption Households}

Figure 3 shows the average electricity consumption profiles for a low-consumption household during the four seasons. In February, a typical low-consumption household consumes $4.89 \mathrm{kWh}$ of electricity in one day. Electricity consumption peaks in the morning and in the evening for this type of household. In May, daily electricity consumption decreases to $2.87 \mathrm{kWh}$ of electricity, which may be linked with the spring weather conditions in Malta in May that do not require heating or cooling for the most part. The daily peaks of consumption also occur in the morning and evening. 


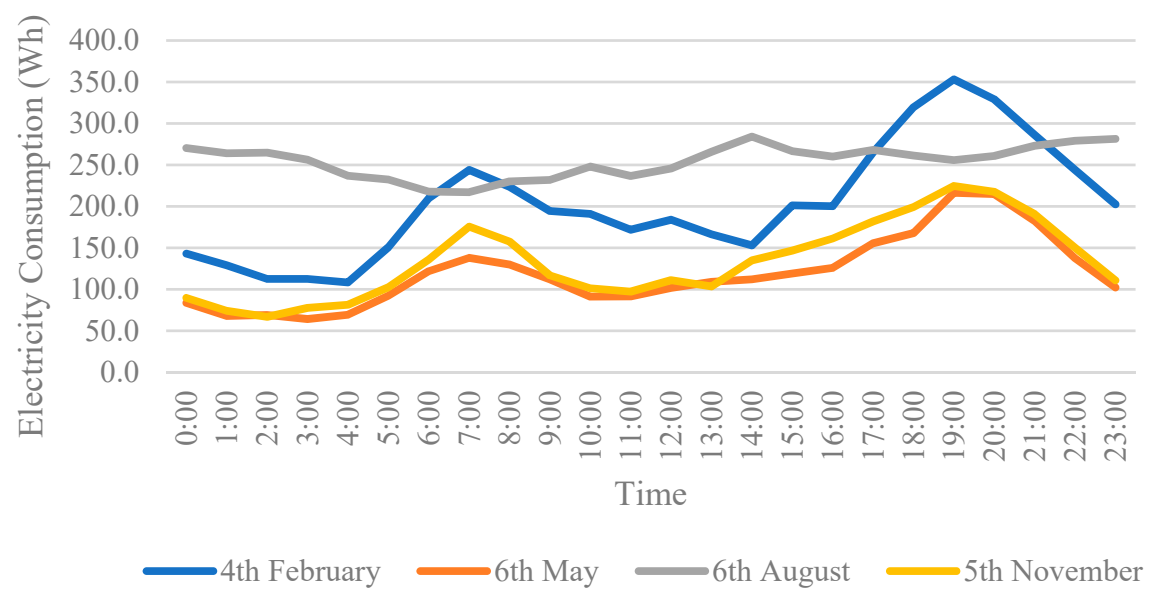

Figure 3. Comparison of the hourly average electricity consumption profiles for a low-consumption household during the four seasons.

On the other hand, in August, one may note the lack of electricity consumption peaks throughout the day. Electricity consumption increases to $6.11 \mathrm{kWh}$ in a day for August, which is more than double that of May but still low to assume cooling is switched on all day. In November, electricity consumption is lower than in summer and the patterns of electricity consumption show a return of the peaks in electricity consumption in the morning and late afternoon. During this month, $3.21 \mathrm{kWh}$ of electricity were consumed in a day.

\subsubsection{Medium-Consumption Households}

Figure 4 shows the average electricity consumption profiles for a medium-consumption household during the four seasons. It can be observed that the pattern of daily electricity consumption is very similar to that of low-consumption households (Figure 3) for all the seasons. However, in February, the electricity consumption for one day was $41.2 \mathrm{kWh}$, which is much higher than the consumption of low-consumption households. In May, the electricity consumption is also significantly lower than that of February for mediumconsumption households, with the peaks of electricity consumption however remaining in the early morning and evening. The total electricity consumed in a day on the 6th May was $23.9 \mathrm{kWh}$.

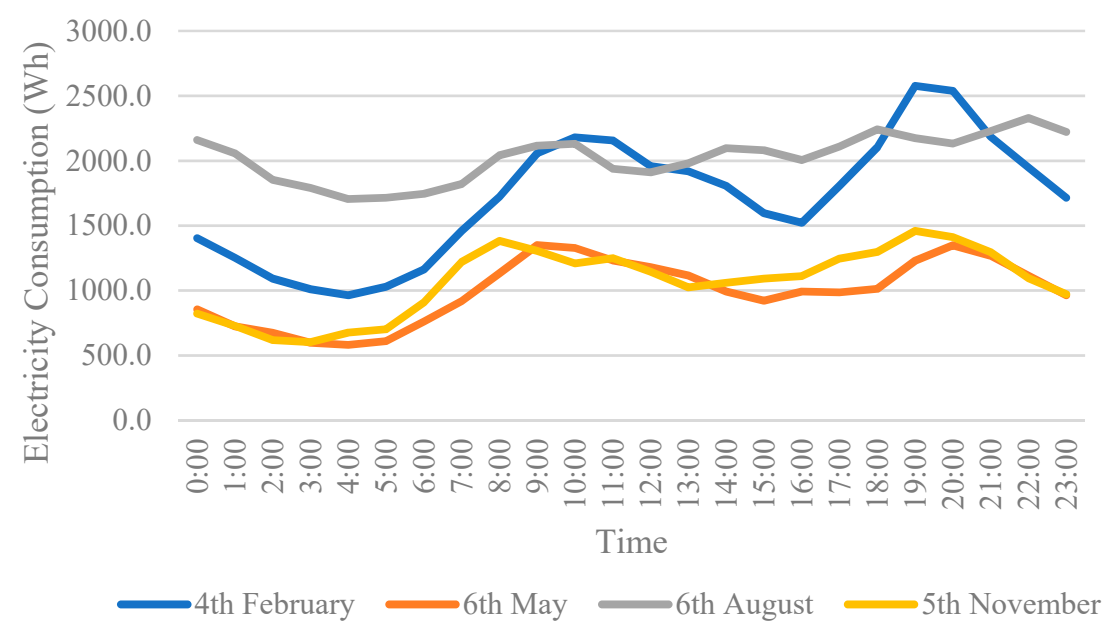

Figure 4. Comparison of the hourly average electricity consumption profiles for a mediumconsumption household during the four seasons.

The daily electricity consumption in August was $48.6 \mathrm{kWh}$ for a medium-consumption household, which is significantly higher than the electricity consumption in spring for 
the same type of household. Once again, the peak in electricity consumption is uniform throughout the day. During November, the daily electricity consumption was $26.6 \mathrm{kWh}$, which is nearly half the electricity consumption on the 6th August.

\subsubsection{High-Consumption Households}

High-consumption households have different patterns of electricity consumption than households with low- and medium-consumption levels. Figure 5 shows the average electricity consumption profiles for a high-consumption household during the four seasons. In February, the morning and evening peaks are significantly reduced since electricity consumption remains high throughout the night and day. In total, $90 \mathrm{kWh}$ of electricity is consumed by a high-consumption household in one day in winter, which is more than double the consumption of a medium-consumption household.

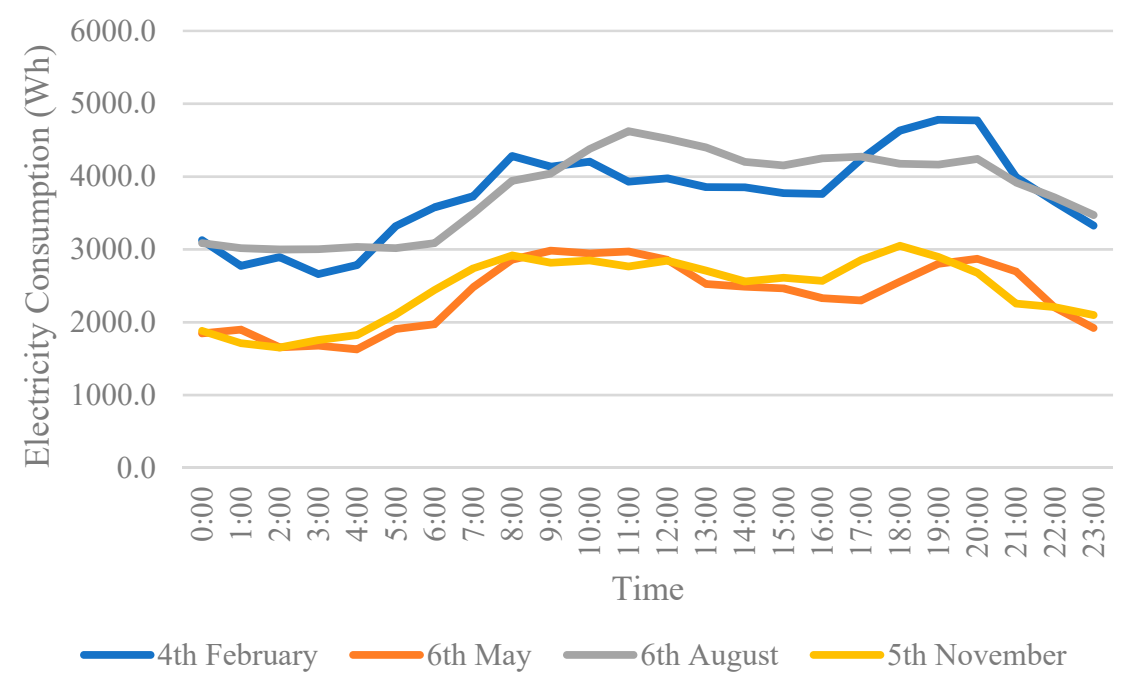

Figure 5. Comparison of the hourly average electricity consumption profiles for a high-consumption household during the four seasons.

Unlike low- and medium-consumption households, the highest peak in energy consumption in May occurs in the morning for high-consumption households, starting at 07:00 and ending at 12:00. During this month, the daily electricity consumption on the 6th May was $56.9 \mathrm{kWh}$. In August, a peak in electricity consumption occurs at 08:00, and remains high all day. In $24 \mathrm{~h}, 91.2 \mathrm{kWh}$ of electricity was consumed by a high-consumption household in August. In November, electricity consumption was once again lower than summer and winter, standing at a daily consumption of $58.8 \mathrm{kWh}$. In this case, the electricity consumption pattern is similar to that of February.

\section{Analysis of Results}

This section will focus on presenting the results for a south-facing PV system installed for medium-consumption households since this is the most common installation scenario within the Maltese Islands. The results for different inclination angles for the south-facing orientation are grouped together to compare electricity generation patterns between each configuration. Electricity consumption data for medium-consumption households are also included in the graphs to allow for the comparison between electricity demand and supply.

\subsection{Results for a South-Facing PV System}

Figure 6 groups the electricity generation of south-facing PV systems with different inclinations and shows an increased difference in electricity generation in winter and summer between the five inclination angles studied. It can be observed how a high inclination angle for a south-facing PV system provides more electricity in winter, while a low inclination angle generates the most electricity in summer. A $30^{\circ} \mathrm{PV}$ system provides 
the most energy over the whole year $\left(0.87 \%\right.$ more than a $40^{\circ}$-inclined system), since electricity generation is similar to a $40^{\circ}$ panel in winter, but higher in summer. The flat panel, and the $10^{\circ}$-inclined PV system are the two configurations that provide the least energy yield in a year, generating $12.4 \%$ and $6 \%$ less than a $30^{\circ}$-inclined system, respectively.

\begin{tabular}{|c|c|c|c|c|c|}
\hline & $0^{\circ} \mathbf{k W h}$ & $10^{\circ} \mathbf{k W h}$ & $20^{\circ} \mathrm{kWh}$ & $30^{\circ} \mathrm{kWh}$ & $40^{\circ} \mathbf{k W h}$ \\
\hline Year & 4413.5 & 4733.8 & 4941.6 & 5036.4 & 4992.8 \\
\hline
\end{tabular}

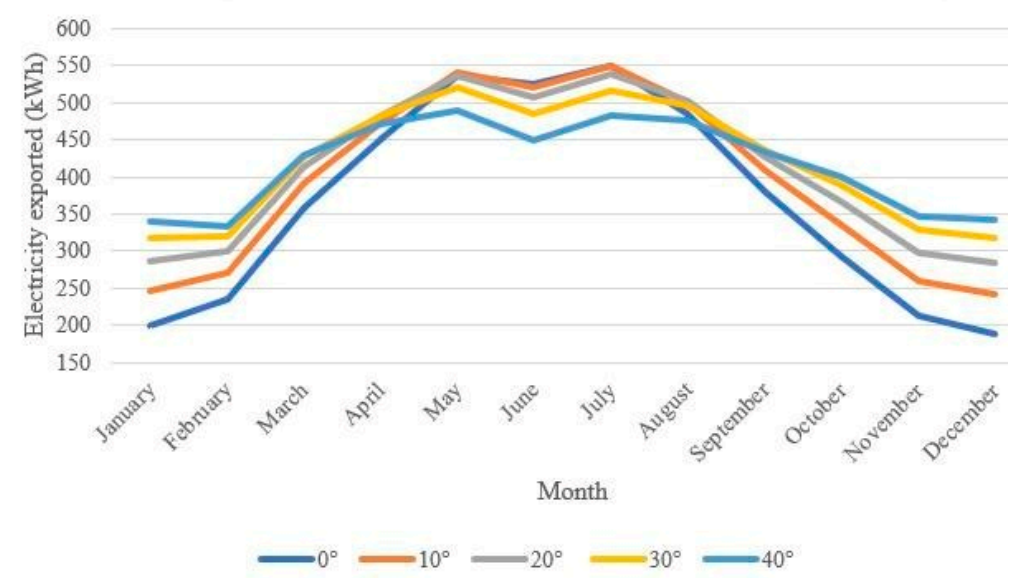

Figure 6. Monthly electricity generation of a $3 \mathrm{kWp}$ south-facing PV system installed with different inclination angles.

When analysing the hourly electricity generation of a south-facing PV system, one may observe a symmetrical energy generation output, with the latter increasing in the morning, reaching a maximum at midday, and decreasing at a similar rate in the afternoon (Figure 7). In February, a panel inclined at $40^{\circ}$ provides the most energy during a day, followed by a panel inclined at $30^{\circ}$. If a panel is installed at $10^{\circ}$, electricity generation will only match the demand of medium-consumption households between 12:00 and 13:00, while a flat panel will never provide enough energy as required to cover electricity demand.

\begin{tabular}{|c|c|c|c|c|c|c|c|}
\hline & Flat Wh & $10^{\circ}$ Wh & $20^{\circ}$ Wh & $30^{\circ}$ Wh & $40^{\circ}$ Wh & Low Wh & Medium Wh \\
\hline Day & 10,940 & 13,135 & 14,894 & 16,202 & 17,068 & 4893 & 41,173 \\
\hline
\end{tabular}

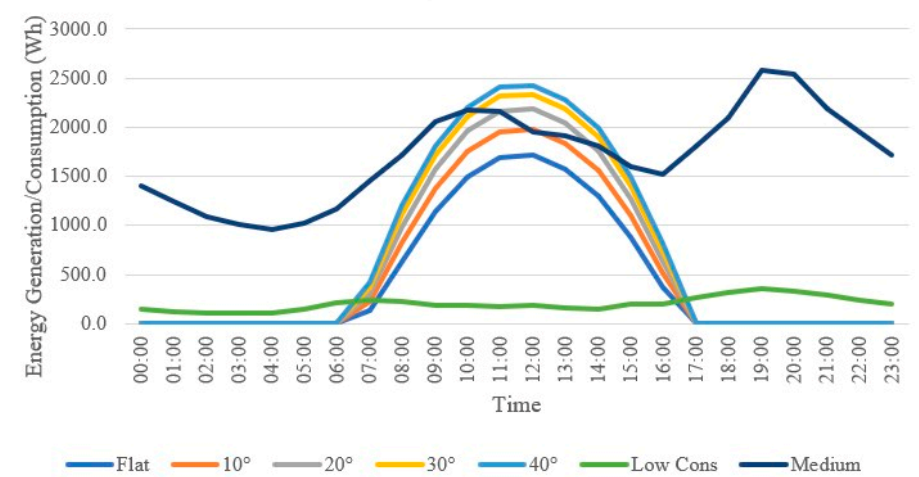

Figure 7. Comparison between hourly electricity generation of a $3 \mathrm{kWp}$ PV system and the patterns of low- and medium-consumption households for a south-facing system in February.

In May, a south-facing PV system with different inclination angles shows a similarity in the electricity generation patterns of each configuration. Although a PV system with $30^{\circ}$ inclination provides the most energy in a day, the other inclinations studied also provide a 
similar amount of daily electricity. The PV system with a $40^{\circ}$ inclination angle provides the least electricity, and when compared with medium-consumption households, this system is the last to match energy requirements in the morning and the first to stop providing enough electricity to cover demand in the afternoon (Figure 8).

\begin{tabular}{|c|c|c|c|c|c|c|c|}
\hline & Flat kWh & $10^{\circ} \mathbf{k W h}$ & $20^{\circ} \mathbf{k W h}$ & $30^{\circ} \mathbf{k W h}$ & $40^{\circ} \mathbf{k W h}$ & Low kWh & Medium kWh \\
\hline Day & 18,210 & 18,491 & 18,346 & 17,778 & 16,793 & 2872 & 23,900 \\
\hline
\end{tabular}

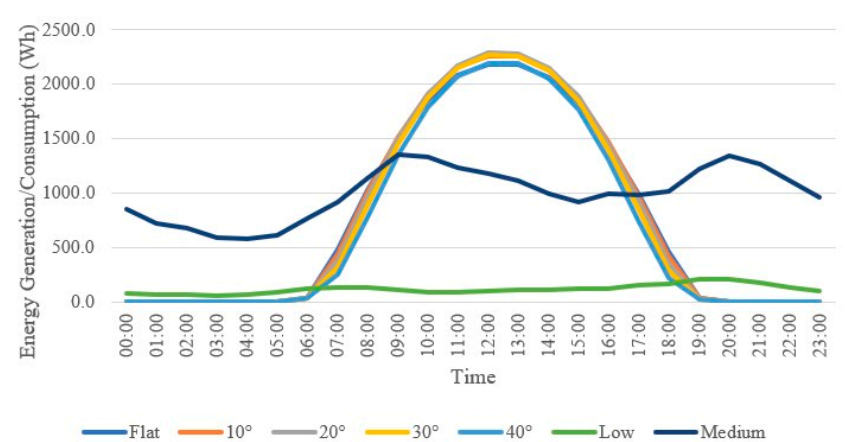

Figure 8. Comparison between hourly electricity generation of a $3 \mathrm{kWp}$ PV system and the patterns of low-, and medium-consumption households for a south-facing system in May.

Electricity generation in August does not match the electricity demand of a mediumconsumption household for most of the day, especially since electricity consumption in August remains high all day. The inclination angle does not have a significant impact on electricity generation during the day. Only the flat panel shows an observable reduction in electricity generation at midday (Figure 9). In this case, a panel inclined at $20^{\circ}$ provides the most electricity, followed by a panel inclined at $10^{\circ}$ and $30^{\circ}$ respectively.

\begin{tabular}{|c|c|c|c|c|c|c|c|}
\hline & Flat kWh & $10^{\circ} \mathrm{kWh}$ & $20^{\circ} \mathrm{kWh}$ & $30^{\circ} \mathrm{kWh}$ & $40^{\circ} \mathrm{kWh}$ & Low kWh & Medium kWh \\
\hline Day & 16,356 & 16,885 & 17,004 & 16,732 & 16,066 & 6107 & 48,590 \\
\hline
\end{tabular}

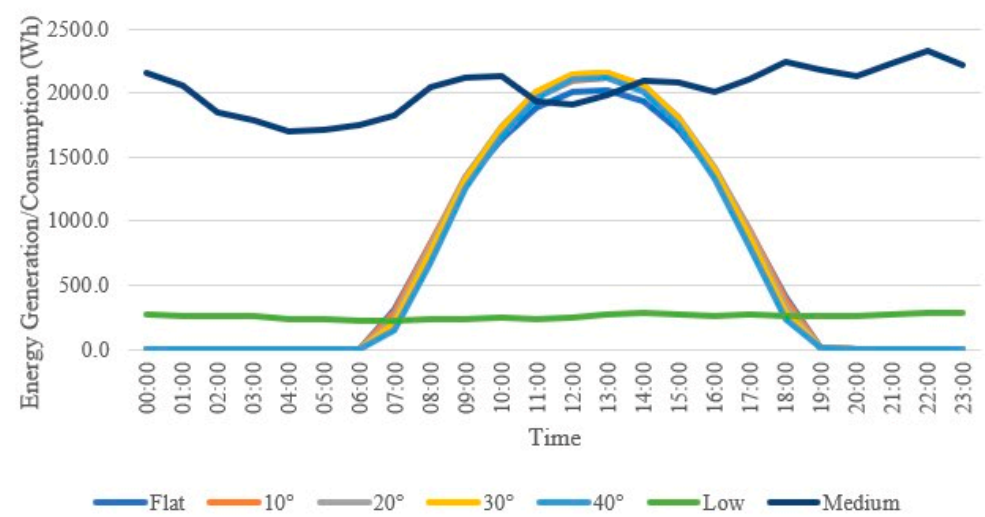

Figure 9. Comparison between hourly electricity generation of a $3 \mathrm{kWp}$ PV system and the patterns of low-, and medium-consumption households for a south-facing system in August.

In November, the electricity consumption of medium-consumption households reduces significantly, permitting electricity generation from inclined PV systems to match demand for several hours. The electricity supply from PV systems with higher inclination angles is the first to match with demand in the morning and the last to drop below demand in the afternoon (Figure 10). A $40^{\circ}$ system provides the most electricity in November. 
Decreasing the inclination angle causes a decrease in electricity generation, with a flat panel providing the least energy yield for the day.

\begin{tabular}{|c|c|c|c|c|c|c|c|}
\hline & Flat kWh & $10^{\circ} \mathbf{k W h}$ & $20^{\circ} \mathbf{k W h}$ & $30^{\circ} \mathbf{k W h}$ & $40^{\circ} \mathbf{k W h}$ & Low kWh & Medium kWh \\
\hline Day & 8118 & 10,213 & 11,930 & 13,265 & 14,211 & 3207 & 25,637 \\
\hline
\end{tabular}

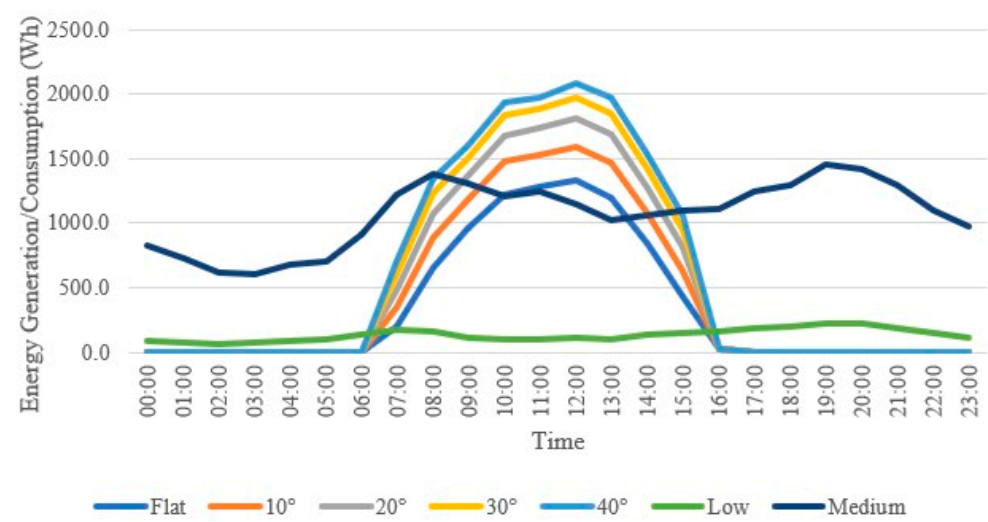

Figure 10. Comparison between hourly electricity generation of a $3 \mathrm{kWp}$ PV system and the patterns of low-, and medium-consumption households for a south-facing system in November.

\subsection{Analysis of Income for Each Configuration}

To understand which configurations provide the best income for residents, the next step was to compare electricity generation and consumption with the cost of electricity and the feed-in tariff available. During hours where electricity generation was higher than electricity consumption, the excess energy was multiplied by the feed-in tariff (€0.155) to export electricity to the grid. Conversely, if electricity consumption was higher than the supply of electricity from the PV system, the amount of electricity required was multiplied by the cost of electricity, which varied depending on the consumption level of the households. The most common scenario in the Maltese Islands are households with a consumption between low and medium thresholds. Although the medium-consumption scenario might be a bit higher than the average consumption, it is the one that most closely approaches it and thus, for this reason, this section once again shows the results obtained for medium-consumption households. In the case of medium-consumption households, a $3 \mathrm{kWp}$ PV system does not generate enough electricity to allow residents to cover the expenditure on electricity imported from the grid. The PV system only comes close to providing enough electricity to cover costs for residents in May, with a south-facing system, inclined at $10^{\circ}$, providing the best result.

Table 2 shows that when considering all four days studied, a south-facing system with a $40^{\circ}$ inclination provides residents with the least expenditure of $€ 22.46$, followed by a south-facing system inclined at $30^{\circ}$ with an expenditure of $€ 22.54$. East- and westfacing configurations result in a significantly higher expenditure on all four days studied, especially when the PV system is installed with a high inclination angle. For many of the configurations, the difference in income from the PV system is less than $10 \%$, while for an east- and west-facing system, the difference increases to around $20 \%$. 
Table 2. Daily cost of electricity per month for medium-consumption households.

\begin{tabular}{|c|c|c|c|c|c|c|}
\hline \multirow[b]{2}{*}{ Orientation } & \multirow[b]{2}{*}{ Inclination $\left({ }^{\circ}\right)$} & \multicolumn{5}{|c|}{ Daily Cost of Electricity per Month $(€)$} \\
\hline & & February & May & August & November & Total \\
\hline Flat & 0 & -10.34 & -0.95 & -11.06 & -2.82 & -25.16 \\
\hline \multirow{4}{*}{ East } & 10 & -10.32 & -0.98 & -11.08 & -2.81 & -25.18 \\
\hline & 20 & -10.34 & -1.06 & -11.20 & -2.81 & -25.41 \\
\hline & 30 & -10.41 & -1.18 & -11.37 & -2.82 & -25.78 \\
\hline & 40 & -10.51 & -1.33 & -11.57 & -2.85 & -26.26 \\
\hline \multirow{4}{*}{ Southeast } & 10 & -9.78 & -0.93 & -10.96 & -2.57 & -24.24 \\
\hline & 20 & -9.37 & -0.97 & -10.97 & -2.38 & -23.68 \\
\hline & 30 & -9.08 & -1.06 & -11.06 & -2.24 & -23.45 \\
\hline & 40 & -8.92 & -1.19 & -11.23 & -2.16 & -23.50 \\
\hline \multirow{4}{*}{ South } & 10 & -9.59 & -0.91 & -10.91 & -2.49 & -23.89 \\
\hline & 20 & -8.99 & -0.93 & -10.89 & -2.22 & -23.02 \\
\hline & 30 & -8.54 & -1.02 & -10.98 & -2.00 & -22.54 \\
\hline & 40 & -8.24 & -1.17 & -11.19 & -1.86 & -22.46 \\
\hline \multirow{4}{*}{ Southwest } & 10 & -9.84 & -0.92 & -10.97 & -2.60 & -24.33 \\
\hline & 20 & -9.47 & -0.96 & -10.98 & -2.43 & -23.84 \\
\hline & 30 & -9.22 & -1.05 & -11.09 & -2.31 & -23.66 \\
\hline & 40 & -9.11 & -1.17 & -11.25 & -2.23 & -23.77 \\
\hline \multirow{4}{*}{ West } & 10 & -10.38 & -0.97 & -11.10 & -2.83 & -25.27 \\
\hline & 20 & -10.47 & -1.05 & -11.23 & -2.84 & -25.59 \\
\hline & 30 & -10.58 & -1.17 & -11.40 & -2.86 & -26.01 \\
\hline & 40 & -10.71 & -1.31 & -11.60 & -2.90 & -26.52 \\
\hline
\end{tabular}

Once the income from each configuration was calculated as listed in Table 2, an attempt at finding a combination of configurations that may increase the overall income from the PV system was made. The results of combining configurations and comparing electricity generation with the consumption of medium-consumption households can be seen in Table 3. The results show no increased benefit from combining two orientations with each other when installing a PV system. A $3 \mathrm{kWp}$ south-facing system provides an overall better income for residents than a PV system installed with $1.5 \mathrm{kWp}$ facing the southeast, and $1.5 \mathrm{kWp}$ facing the southwest on all the days studied.

Table 3. Daily cost of electricity per month for medium-consumption households when combining configurations.

\begin{tabular}{ccccccc}
\hline & \multicolumn{5}{c}{ Daily Cost of Electricity per Month $(\boldsymbol{€})$} \\
\hline Orientation & Inclination $\mathbf{(}^{(\mathbf{})}$ & February & May & August & November & Total \\
\hline \multirow{3}{*}{ East-West } & 10 & -10.35 & -0.97 & -11.09 & -2.82 & -25.23 \\
& 20 & -10.40 & -1.05 & -11.21 & -2.83 & -25.50 \\
& 30 & -10.49 & -1.18 & -11.38 & -2.84 & -25.90 \\
& 40 & -10.61 & -1.32 & -11.59 & -2.87 & -26.39 \\
\hline \multirow{3}{*}{ Southeast } & 10 & -9.81 & -0.93 & -10.97 & -2.58 & -24.29 \\
Southwest & 20 & -9.42 & -0.96 & -10.98 & -2.40 & -23.76 \\
& 30 & -9.15 & -1.05 & -11.08 & -2.28 & -23.56 \\
& 40 & -9.02 & -1.18 & -11.24 & -2.20 & -23.63 \\
\hline
\end{tabular}

\section{Discussion}

The results collected from PVsyst and presented in Sections 3 and 4 show that a south-facing system with a $30^{\circ}$ inclination provides the most electricity during the whole year. However, when considering the electricity consumption patterns of low-, mediumand high-consumption households, it has been concluded that a south-facing PV system, inclined at $40^{\circ}$, provides better income for residents throughout the four seasons. This 
does not mean that these configurations are the only ones that should be considered. This section will provide a discussion of the results, with the aim of understanding the benefits of each configuration to allow residents to make an informed decision when installing a PV system in their home.

\subsection{Matching Electricity Demand}

The demand for electricity in Malta changes according to the time of the year, with summer and winter being periods of high demand, and autumn and spring being periods of low demand. For this reason, it is important for Malta to generate as much electricity as possible during times of high demand to reduce the load placed on the country's electricity generation plants. For instance, while a south-facing PV system with a $30^{\circ}$ inclination generates the most electricity over a whole year, a PV system with the same orientation but a $40^{\circ}$ inclination angle may prove to be more beneficial since the electricity generated in winter helps residents reduce their consumption during a period of high demand.

One possibility to improve electricity generation in winter, while also preventing a drop in electricity supply in summer could be to install a system that changes its inclination according to the season. For example, if one could install a south-facing system with $40^{\circ}$ inclination in winter that can be adjusted to $20^{\circ}$ in summer, one would obtain the best electricity generation when the sun is low in the sky, while not inhibiting energy yield during the summer months. In this case, the expenditure of medium-consumption households will decrease to $€ 21.92$. Besides allowing residents to generate more electricity and reduce their electricity bills even further, this installation technique will thus help any country reduce its demand for electricity from the electricity generation plants during the months when the demand is highest since it serves to maximise electricity generation in both the summer and winter months.

When considering hourly electricity consumption patterns, it is important to understand that each household has varying consumption patterns, which means that one configuration may never be the solution for all. Since for most of the year, demand for electricity is high in the morning, a southeast-facing PV system may allow the residents to benefit from increased supply during the times of highest demand. The reason for electricity supply being higher in the morning is that the sun rises from the east, which means that since the PV system is facing that direction, it will receive more direct solar irradiation in the morning.

Another possibility to decrease the mismatch between demand and supply is to install a PV system using two orientations. For example, one could cater for the morning increase in demand by installing a set of PV panels facing the southeast, while also installing a set of PV panels facing the south or southwest to prevent a decrease in electricity supply during the second part of the day. While this may not prove to be the most economical solution for residents, it may help reduce their dependency on imported electricity during times of high demand.

\subsection{Maximising Income}

If one considers solely electricity generation, a south-facing PV system, inclined at $30^{\circ}$ provides residents with the most electricity, and therefore the most income from the PV system. However, the cost of electricity during the four seasons must be considered to understand the true income that the PV system provides. This study showed that a southfacing PV system inclined at $40^{\circ}$ may provide more income for residents during a whole year, since the increased generation of electricity prevents residents from paying a higher tariff during winter, when demand is high. It is important to note that the calculations for this study were based on the presence of a feed-in tariff ( $€ 0.155)$ that is given to residents for several years. Once the feed-in tariff expires, electricity generated from the PV system and sold to the grid will be sold at a lower price, suggesting that it would make even more sense for residents to reduce the gap between energy generation and demand through self-consumption. 


\subsection{Energy Storage}

The possibility of energy storage was not considered in this study since with the implementation of an energy storage system, the need to configure the PV system in certain ways will be removed. The authors believe that the installation of energy storage systems such as batteries is the way forward. However, at the time of writing, the installation of such systems is still not economically feasible on a residential scale and requires the introduction of more grants to aid residents to reduce the cost of installing such systems [25]. In 2020, Malta introduced the first of its kind grant for energy storage systems that however covered only up to $25 \%$ of the cost of the system [26].

If a high-consumption household had to install a PV system able to cover its entire daily energy requirements ( $90 \mathrm{kWh}$ in February), a $17 \mathrm{kWp}$ PV system would be required. This, of course, must be coupled with a battery-storage system since electricity generation from PV systems only occurs during sunlight hours. If one considers that the battery's depth of discharge (DoD) should be 55\% [27] and full self-reliance for one day, then the battery storage system must have a capacity of $101 \mathrm{kWh}$ of electricity to allow the household to get through all the hours where electricity generation is less than electricity demand. Medium-consumption households have a daily consumption of $41 \mathrm{kWh}$ in February. In this case, the required size of the PV system to cater for an entire day should be at least 8 $\mathrm{kWp}$. The battery storage capacity, when considering the same factors as high-consumption households, should be at least $46 \mathrm{kWh}$.

In an article written by Comello and Reichelstein [28], it is estimated that the levelized cost of electricity of a rooftop PV system installed with battery storage may reduce to $€ 0.065$ within the next four years if the cost of lithium-ion batteries continues to decrease with the current trend. This suggests that the possibility of investing in battery storage systems in the future will allow residents to increase the benefits received from their PV system, while also reducing their dependency on the country's electricity generation plants for energy. In fact, recent government grants in Malta have already started to include specific grants of battery storage to incentivise such an investment.

\section{Conclusions}

This study has presented the results for the production profile of various PV system setups and their income potential, followed by a comparison of the electricity generation from each configuration with electricity consumption patterns of households. Such results have ascertained which configurations provide the most economic benefit to residents. This section aims to conclude this study by discussing the key findings, as well as by presenting a summary of the results together with a few recommendations and suggestions for future research. Government regulators, planning authorities as well as installation companies may find the results of this study useful to understand how to increase the benefits related with solar technologies, while researchers and students may wish to use this study to further develop their skills and to understand what further research may be conducted to increase the benefits of solar energy.

\subsection{Key Findings}

The results of this study have confirmed that a south-facing PV system provides the most income to residents for each inclination angle studied. However, both a southeastfacing and a southwest-facing PV system were found to still provide a similar income during the four seasons studied. A southeast-facing PV system with $20^{\circ}$ inclination or higher also allows the peak of electricity generation to shift slightly to the morning, which is a time where electricity demand from the country's electricity generation plants is high. This suggests that, although a south-facing system may provide the most income for residents, a southeast-facing system may help residents reduce their dependency on imported electricity during times of high demand, which in turn, will allow Malta to reduce the mismatch between electricity supply from renewable energy and demand. 
Another aim of this study was to determine whether the electricity consumption patterns of households may impact the optimal configurations for PV systems in Malta. The results have shown that a south-facing PV system inclined at $30^{\circ}$ generates the most electricity in a year in Malta. However, when the hourly electricity generation on four days of the year (one day in each season) is compared with the electricity consumption patterns of households, a south-facing PV system inclined at $40^{\circ}$ generates the most income for residents.

By observing the graphs for each inclination angle studied in Section 4.1, and by comparing the income of each configuration in different months, one may note how changing the inclination angle of the PV system during the four seasons may help residents generate the most income over one whole year. This study has found that a $40^{\circ}$-inclined PV system generates the most electricity on the days studied in February and November, while a $10^{\circ}$-or $20^{\circ}$-inclined PV system captures the most energy in May and August.

\subsection{Recommendations}

It is recommended that residents consider various configurations depending on their requirements before deciding on which configuration to use for installing their PV system. One possibility for future investment schemes is to provide a higher feed-in tariff for electricity generated in times of high demand on the country's electricity generation plants. This will help improve the income of PV systems installed while maximising energy yield during these times.

Another recommendation is to consider PV systems that can vary their inclination angle during the year. The results show that a PV system with a high inclination helps to improve income significantly in winter, while the opposite is true for summer. A manual system that allows for this change twice a year $\left(40^{\circ}\right.$ in winter and $20^{\circ}$ in summer) could probably be included in future installations at a minimal cost, while increasing potential generation by around 3-5\%.

An interesting possibility for future research will be to compare the income that can be obtained by opting for an energy storage system with that obtained by opting to sell electricity to the grid. Since the government scheme for energy storage systems introduced in Malta [26] was closed in December 2020, such an analysis should be performed upon the success of this grant to determine if future schemes can help residents increase the income potential from investing in a PV system.

A possibility for future studies is to analyse the economic benefit of installing PV systems that can change their inclination to fixed points during the year by comparing the increase in electricity generation with the increase in costs related to the installation and maintenance of the additional moving parts.

Author Contributions: Conceptualisation, M.D. and L.M.S.; methodology, D.Z., M.D. and L.M.S.; software, D.Z.; validation, M.D. and L.M.S.; formal analysis, D.Z.; investigation, D.Z.; resources, L.M.S.; data curation, D.Z.; writing—original draft preparation, M.D.; writing—review and editing, D.Z., M.D. and L.M.S.; visualisation, D.Z. and M.D.; supervision, M.D. and L.M.S.; project administration, M.D. and L.M.S. All authors have read and agreed to the published version of the manuscript.

Funding: This research received no external funding.

Institutional Review Board Statement: Not applicable.

Informed Consent Statement: Not applicable.

Data Availability Statement: The data presented in this study are available on request from the corresponding author. The data are not publicly available due to the fact that some of the data are obtained from Enemalta, and the Energy and Water Agency, and are available from the authors with the permission of relevant third parties. 
Acknowledgments: The authors would like to acknowledge the support from Enemalta and the Energy and Water Agency in Malta that readily provided the household consumption data required to conduct this study.

Conflicts of Interest: The authors declare no conflict of interest.

\section{References}

1. Abd-ur-Rehman, H.M.; Al-Sulaiman, F.A.; Mehmood, A.; Shakir, S.; Umer, M. The potential of energy savings and the prospects of cleaner energy production by solar energy integration in the residential buildings of Saudi Arabia. J. Clean. Prod. 2018, 183, 1122-1130. [CrossRef]

2. Li, C.; Zhou, D.; Zheng, Y. Techno-economic comparative study of grid-connected PV power systems in five climate zones, China Energy 2018, 165, 1352-1369. [CrossRef]

3. Xu, X.; Li, J.; Xu, Y.; Xu, Z.; Lai, C.S. A Two-stage game-Theoretic method for residential pv panels planning considering energy sharing mechanism. IEEE Trans. Power Syst. 2020, 35, 3562-3573. [CrossRef]

4. Bueno, J.; Romero-Jordán, D.; del Río, P. Analysing the drivers of electricity demand in Spain after the economic crisis. Energies 2020, 13, 5336. [CrossRef]

5. Palm, J. Household installation of solar panels-Motives and barriers in a 10-year perspective. Energy Policy 2018, 113, 1-8. [CrossRef]

6. Poudyal, R.; Loskot, P.; Parajuli, R. Techno-economic feasibility analysis of a 3-kW PV system installation in Nepal. Renew. Wind. Water Sol. 2021, 8, 1-18. [CrossRef]

7. Timilsina, R. Are renewable energy technologies cost competitive for electricity generation? Renew. Energy 2021, 180, 658-672. [CrossRef]

8. European Commission. Assessment of the Final National Energy and Climate Plan of Malta; European Union: Brussels, Belgium, 2020

9. Komilov, A. Location and orientation based LCOE: Simplified visual analysis and generalization of the levelized cost of electricity from storageless photovoltaic systems. Int. J. Energy Res. 2021, 45, 5649-5658. [CrossRef]

10. Benda, D.; Chu, X.; Sun, S.; Quek, T.Q.S.; Buckley, A. PV cell orientation angle optimization for a solar energy harvesting base station. In Proceedings of the GLOBECOM 2017-2017 IEEE Global Communications Conference, Singapore, 4-8 December 2017 pp. 1-6.

11. Sustainable Energy Authority of Ireland. Best Practice Guide—Photovoltaics (PV); Sustainable Energy Authority of Ireland: Dublin, Ireland, 2019.

12. Yassir, A. Genetic Algorithm as a Solutions Optimization of Tilt Angles for Monthly Periods of Photovoltaic Installation. In Proceedings of the International Conference on Science and Innovated Engineering (I-COSINE), Aceh, Indonesia, 21-22 October 2018.

13. Nfaoui, M.; El-Hami, K. Extracting the maximum energy from solar panels. Energy Rep. 2018, 4, 536-545. [CrossRef]

14. Matchanov, N.A.; Seok, K.O.; Mirzaev, A.A.; Malikov, M.A.; Saidov, D.S. Study of Energy Yield on Grid Connected Micro-Inverter Type 2.24 kW PV System Using PVsyst Simulation Software. Appl. Sol. Energy 2020, 56, 263-269. [CrossRef]

15. Nussbaumer, H.; Janssen, G.; Berrian, D.; Wittmer, B.; Klenk, M.; Baumann, T.; Baumgartner, F.; Morfa, M.; Burgers, A.; Libalc, J.; et al. Accuracy of simulated data for bifacial systems with varying tilt angles and share of diffuse radiation. Sol. Energy 2020, 197, 6-21. [CrossRef]

16. Stagno, L.M.; Yousif, C.; Rubén, E.; Palacios, V. Solar Photovoltaic Systems Performance in Malta: Potential Versus Real Contribution to the 2020 Re Target. In Proceedings of the 26th European Photovoltaic Solar Energy Conference and Exhibition, Hamburg, Germany, 5-9 September 2011.

17. Interreg Europe. Photovoltaic Panels in Malta (Part I). 2020. Available online: https://www.interregeurope.eu/resindustry/ news/news-article/9795/photovoltaic-panels-in-malta/ (accessed on 15 November 2021).

18. ODYSSEE-MURE. Malta energy efficiency \& Trends policies. In Malta Profile; ODYSSEE-MURE: Enerdata, Malta, 2021.

19. Victoria, M.; Andresen, G.B. Using validated reanalysis data to investigate the impact of the PV system configurations at high penetration levels in European countries. Prog. Photovolt. Res. Appl. 2019, 27, 576-592. [CrossRef]

20. NSO. Electricity Supply: 2015-2019. 2020. Available online: https://nso.gov.mt/en/News_Releases/Documents/2020/10/ News2020_161.pdf (accessed on 20 October 2020).

21. NSO. Electricity Supply: 2014-2018. 2019. Available online: https://nso.gov.mt/en/News_Releases/View_by_Unit/Unit_02 /Regional_and_Geospatial_Statistics/Documents/2019/News2019_163.pdf (accessed on 5 May 2020).

22. PVsyst. Overview > General Description of the PVsyst Software. 2020. Available online: https://www.pvsyst.com/help/ general_descr.htm (accessed on 2 August 2020).

23. PVsyst. Physical Models Used > Irradiation Models > Transposition Model. Available online: https://www.pvsyst.com/help/ models_meteo_transposition.htm (accessed on 27 October 2020).

24. Sandia National Laboratories. PV Performance Modeling Collaborative I Perez Sky Diffuse Model. 2018. Available online: https:/ / pvpmc.sandia.gov/modeling-steps/1-weather-design-inputs/plane-of-array-poa-irradiance/calculating-poairradiance/poa-sky-diffuse/perez-sky-diffuse-model/ (accessed on 27 October 2020).

25. Puranen, P.; Kosonen, A.; Ahola, J. Techno-economic viability of energy storage concepts combined with a residential solar photovoltaic system: A case study from Finland. Appl. Energy 2021, 298, 117199. [CrossRef] 
26. Regulator for Energy and Water Services. 2020 Battery Storage Scheme. 2021. Available online: https://www.rews.org.mt/\#/en/ sdgr/440-2020-battery-storage-scheme (accessed on 17 February 2021).

27. Hemmati, R. Optimal design and operation of energy storage systems and generators in the network installed with wind turbines considering practical characteristics of storage units as design variable. J. Clean. Prod. 2018, 185, 680-693. [CrossRef]

28. Comello, S.; Reichelstein, S. The emergence of cost effective battery storage. Nat. Commun. 2019, 10, 2038. [CrossRef] [PubMed] 